\title{
PSICOPATOLOGÍA PSICOANALÍTICA EN LA CLÍNICA ACTUAL
}

\author{
Francisco Ameglio, Florencia Balseiro \& Mariana Bentancur
}

\author{
Reseña ${ }^{1}$ a cargo de la Magister Cristina \\ López de Caiafa, docente del programa de \\ Maestría en Psicoterapia, orientación Niños \\ y Adolescentes, Facultad de Psicología. \\ Universidad Católica del Uruguay. \\ Docente Titular de la Asociación \\ Psicoanalítica del Uruguay y de la Clínica \\ Prego. Montevideo, Uruguay.
}

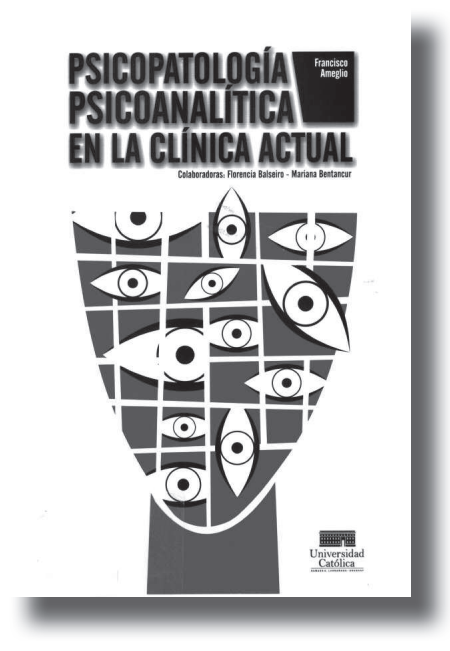

Este libro, que tengo el agrado y el honor de prologar, constituye un aporte valioso y básico para los jóvenes estudiantes que comienzan a adentrarse en el complejo e inquietante mundo de la psicopatología.

La propuesta de Francisco Ameglio y sus colaboradores al plantear una psicopatología dinámica nutrida en las fuentes de la clínica psicoanalítica trasciende lo nosográfico al complejizarlo, enriquecerlo e incluso humanizarlo al colocar en primer plano al sufrimiento y la trama que singulariza al sujeto en su padecer. A la vez, y para comenzar a comprenderlo, presentan y subrayan el trabajo con una causalidad diferente, una causalidad psíquica, no lineal, marcada por lo histórico vivencial. Una causalidad tejida entre impulsos, deseos y fantasías investidas con afecto que pugnan por no ser sofocadas por fuertes rechazos internos, multicausalidad entonces, que hace a la polisemia sintomática.

En el punto de partida, una sólida impronta psicoanalítica nos ubica frente a la angustia fenómeno; proceso y concepto central para pensar el sufrimiento humano, pero no solo el sufrimiento, ya que la angustia y las defensas erigidas contra ella marcan, desde Freud en adelante, hitos en la estructuración del psiquismo, así como en las dinámicas de lo psicopatológico.

Los autores van describiendo y conceptualizando con fineza las angustias, sus variedades y manifestaciones en enfoques que recorren y entraman aportes de diversos autores, recogiendo la pluralidad y riqueza del amplio campo del psicoanálisis actual.

Unas palabras sobre la forma como han estructurado la presentación de los grandes cuadros psicopatológicos a partir del segundo capítulo.

Pienso que es un acierto didáctico el diseño de un recorrido que se reitera en los diferentes capítulos y patologías porque propone un modelo de abordaje integrativo. Primero la

1 (N. de la Ed.) En esta reseña se transcribe el Prólogo realizado por la Prof. Cristina López de Caiafa, bajo el permiso del Grupo Magro. 
presentación teórico conceptual, luego los aspectos semiológicos y diagnósticos tal como en la actualidad los maneja el DSM IV, un "idioma" que es necesario para los intercambios. Luego se despliega la discusión de la psicodinámica con los aportes de diversos autores con perspectivas y enfoques singulares. Este "apronte" teórico clínico da paso luego al ejemplificar con casos clínicos o del acervo literario o filmográfico. Presencia encarnada del funcionamiento psicopatológico que repercute en el lector en forma de una convocatoria y movilización más personal e íntima lo que habilita y abona el trabajo en el eje transferencia contratransferencia.

Finalmente, los cuadros comparativos contribuyen a delimitar, subrayar y organizar puntos nodales de cada enfoque.

Para finalizar, mi beneplácito por este aporte y el deseo que Ameglio y colaboradores se alisten para el próximo.

Ameglio, F., Balseiro, F. \& Bentancur, M. (2012). Psicopatología psicoanalítica en la clínica actual. Montevideo: Magro 